\title{
A multifaceted view on the impacts of shrub encroachment
}

Fernando T. Maestre ${ }^{1, *}$, David J. Eldridge ${ }^{2}$ \& Santiago Soliveres ${ }^{3}$

${ }^{1}$ Departamento de Biología y Geología, Física y Química Inorgánica, Escuela

Superior de Ciencias Experimentales y Tecnología, Universidad Rey Juan Carlos, Calle Tulipán s/n, 28933 Móstoles, Spain.

${ }^{2}$ School of Biological, Earth and Environmental Sciences, University of New South

Wales, Sydney, New South Wales 2052, Australia.

${ }^{3}$ Institute of Plant Sciences, University of Bern, Altenbergrain 21, 3013 Bern, Switzerland

*Author for correspondence: fernando.maestre@urjc.es

\begin{abstract}
Shrub encroachment, a global phenomenon with management implications, is examined in two papers in the current issue of Applied Vegetation Science. Barbosa da Silva et al. show that encroachment simplifies herbaceous community, and Pittarello et al. illustrate how pastoral practices can restore encroached grasslands. While detrimental effects of shrub encroachment on grassland vegetation are often reported, we argue for a more holistic view when assessing this land cover change.
\end{abstract}

\section{Main text}

The increase in the density and cover of native shrubs, particularly in grasslands and open woodlands (shrub encroachment, also known as woody encroachment or thickening), is a global phenomenon that occurs in ecosystems ranging from the drylands of eastern Australia to the tundra (Eldridge et al. 2011). Regardless of the mechanisms driving this land cover change, shrub encroachment is a source of concern for land managers in grasslands worldwide, who consider it a major threat to the viability of their pastoral enterprises (Eldridge \& Soliveres 2015). Within the scientific community, shrub encroachment has often been viewed as being associated 
with declining ecosystem functioning, landscape degradation or desertification (Van Auken 2000). Consequently, considerable resources have been allocated to support shrub removal programs in areas affected by shrub encroachment in countries such as Australia and the USA (Eldridge \& Soliveres 2015). Most of these programs, however, have failed in the long run (e.g. Rango et al. 2005).

Interest in shrub encroachment has not waned in recent years. The two articles included in this issue of Applied Vegetation Science evaluate the consequences of encroachment for grassland vegetation and possible management actions to reverse its negative effects on grasses. Barbosa da Silva et al. (2016) show that shrub encroachment simplified a herbaceous community in seasonally flooded grasslands from the Pantanal ecosystem in Brazil, and Pittarello et al. (2016) illustrate how two management actions, the arrangement of temporary night camp areas and the strategic placement of mineral mix supplements for cattle, can be used to restore the cover, diversity and biomass of grasses in encroached grasslands from the Italian Alps. Both articles provide useful insights into the (deleterious) effects of shrub encroachment on grass diversity and abundance in these ecosystems and how it can be managed to maximize the provision of forage for livestock.

While the results and conclusions of Barbosa da Silva et al. (2016) and Pittarello et al. (2016) are entirely valid, both studies focus on a particular functional group (grasses) and ecosystem service (provision of forage). Can these findings be extended to other environments, the multiple services provided by grasslands/shrublands, the different species of encroaching species, or the variety of taxa from these ecosystems? The response is clearly no, as shrub encroachment has multiple outcomes for the biota, functions and services of terrestrial ecosystems (Fig. 1). Despite so, the shrub encroachment-degradation relationship is generally viewed as a one-size-fits-all paradigm (Van Auken 2000; Eldridge et al. 2011). Increasing evidence suggests that the positive effects of encroachment might far outweigh the perceived negative effects. More recent global-scale field studies (Soliveres et al. 2014) and regional syntheses (Eldridge \& Soliveres 2015) indicate that plant diversity and multiple ecosystem functions are maximized under moderate levels of woody plant cover (the same response reported by Barbosa da Silva et al. [2016] for species diversity). Furthermore, the effects of shrub encroachment on ecosystem structure and functioning, either positive or negative, are strongly dependent on the functional traits 
of both the encroaching shrubs and the grasses being replaced (Maestre et al. 2009), as well as on environmental conditions (e.g. climate; Eldridge et al. 2011) and grazing pressure (Eldridge \& Soliveres 2015). We question whether the use of value-laden language with negative connotations such as "This study is focused on the spread of a native species that behaves as an invasive species” (Barbosa da Silva et al. 2016) does really advance our understanding of shrub encroachment, and whether native encroacher species can be considered analogous to exotics. This view might often be too simple and does not recognize the many positive benefits of shrubs and shrublands over and above any purely pastoral (grazing) value.

The majority of the criticism of encroachment derives from grass/pastoralfocused studies, and relates to its negative effects on forage production. However, shrub encroachment is a complex and multifaceted phenomenon, and understanding its ecological consequences requires that we adopt a more holistic view, acknowledging the multiplicity of organisms and ecosystem processes/services it affects. We call for a greater understanding of the full range of ecological impacts of encroachment and reinforce the notion that any effects are context-dependent. Our perception of shrub encroachment will change markedly depending on those organisms and ecosystem services that we value the most in any ecosystem undergoing such a dramatic land cover change.

\section{Acknowledgments}

We thank John Morgan for the invitation to write this commentary and Meelis Pärtel for the comments provided. FTM acknowledges support from the European Research Council (BIODESERT project, ERC Grant agreement $n^{\circ}$ 647038) and by the Spanish Ministry of Economy and Competitiveness (BIOMOD project, CGL2013-44661-R). DJE was supported by the Hermon Slade Foundation (RG133197).

\section{References}

Barbosa da Silva, F.H., Arieira, J., Parolin, P., Nunes da Cunha, C. \& Junk, W.J. 2016. Shrub encroachment influences herbaceous communities in flooded grasslands of a neotropical savanna wetland. Applied Vegetation Science 19: \#\#\#-\#\#\#.

Eldridge, D.J., Bowker, M.A., Maestre, F.T., Roger, E., Reynolds, J.F., \& Whitford, W.G. 2011. Impacts of shrub encroachment on ecosystem structure and functioning: towards a global synthesis. Ecology Letters 14: 709-722. 
Eldridge, D.J. \& Soliveres, S. 2015. Are shrubs really a sign of declining ecosystem function? Disentangling the myths and truths of woody encroachment in Australia. Australian Journal of Botany 62: 594-608.

Maestre, F.T., Bowker, M.A., Puche, M.D., Hinojosa, M.B., Martínez, I., GarcíaPalacios, P., Castillo, A.P., Soliveres, S., Luzuriaga, A.L., (...) \& Escudero, A. 2009. Shrub encroachment can reverse desertification in Mediterranean semiarid grasslands. Ecology Letters 12: 930-941.

Pittarello, M., Probo, M., Lonati, M. \& Lombardi, G. 2016. Restoration of sub-alpine shrub-encroached grasslands through pastoral practices: effects on vegetation structure and botanical composition. Applied Vegetation Science 19: \#\#\#-\#\#\#.

Rango, A., Huenneke, L., Buonopane M., Herrick, J.E. \& Havstad, K.M. 2005. Using historic data to assess effectiveness of shrub removal in southern New Mexico. Journal of Arid Environments 62: 75-91.

Soliveres, S., Maestre, F.T., Eldridge, D.J., Delgado-Baquerizo, M., Quero, J.L., Bowker, M. A., \& Gallardo, A. 2014. Plant diversity and ecosystem multifunctionality peak at intermediate levels of woody cover in global drylands. Global Ecology and Biogeography 23: 1408-1416.

Van Auken, O.W. 2000. Shrub invasions of North American semiarid grasslands. Annual Review of Ecology and Systematics 31: 197-215. 

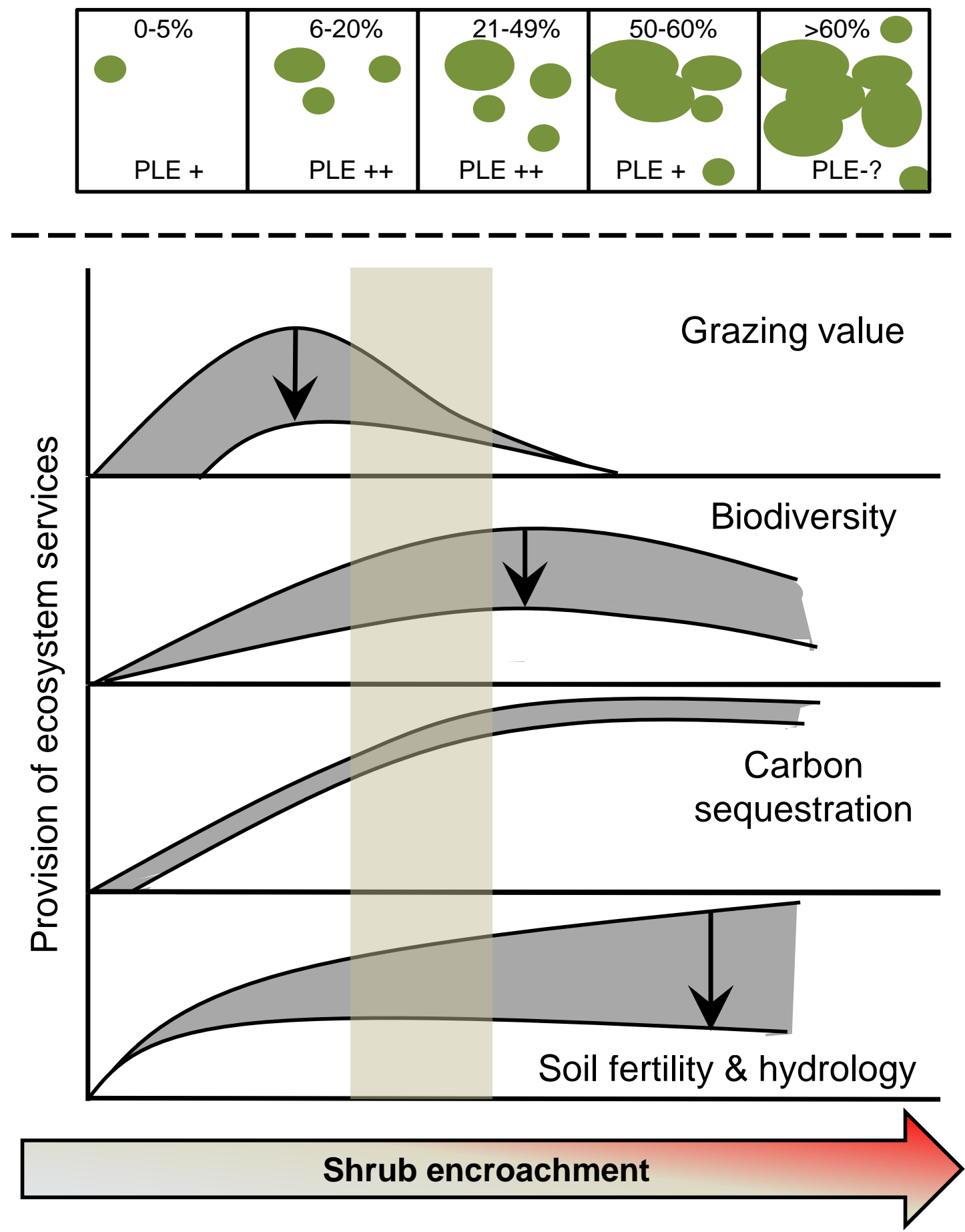

Figure 1. The positive effects of individual shrub patches (PLE) on multiple ecosystem services across Australian woodlands is predicted to remain positive until woody cover reaches about 60\% (upper panel). The lower panel depicts the predicted responses of five ecosystem services to increasing shrub encroachment, with the range of values shown in the shaded envelope. The vertical stripe represents the range of woody cover values that maximize the level of all ecosystem services simultaneously. Modified from Eldridge \& Soliveres (2015). 